\title{
The Living Gesture and the Signifying Moment
}

\author{
Eugene Halton \\ University of Notre Dame
}

\begin{abstract}
Drawing from Peircean semiotics, from the Greek conception of phronesis, and from considerations of bodily awareness as a basis of reasonableness, I attempt to show how the living gesture touches our deepest signifying nature, the self, and public life. Gestural bodily awareness, more than knowledge, connects us with the very conditions out of which the human body evolved into its present condition and remains a vital resource in the face of a devitalizing, rationalistic consumption culture. It may be precisely these deep-rooted abilities for what I term "self-originated experience" that can ultimately offset automatism.
\end{abstract}

\section{UNDERSTANDING WITHOUT WORDS}

One can lie with the mouth, but with the accompanying grimace one nevertheless tells the truth.

-Nietzsche

Conversation in gestures may be carried on which cannot be translated into articulate speech. This is also true of the lower animals. Dogs approaching each other in hostile attitude carry on such a language of gestures. They walk around each other, growling and snapping, and waiting for the opportunity to attack.

-Mead 1934:13-14

Imagine creatures who gather together to bay and rub sticks and hairs together and blow through tubes, in front of creatures who sit silently and, only after the soundritual is completed, respond by showing teeth and hitting open hands together, and, when they really get going, stomping feet in a frenzy of gesturalized emotion. Ah civilization! Ah Homo symphonicus!

Though we like to think of ourselves as creatures of the tongue, communication between people is largely rooted in conversations of gestures. We converse in public contexts through our faces and gazes and bodily language, through mostly subconscious gestures of communication and entrancement, and not simply through our verbal utterances (Birdwhistell 1970; Darwin [1872] 1998; Hall 1959, 1967, 1983).

Direct all correspondence to Eugene Halton, Sociology and American Studies, Decio Hall 166, University of Notre Dame, Notre Dame, IN 46556; e-mail: Eugene.W.Halton.2@nd.edu.

Symbolic Interaction, Volume 27, Number 1, pages 89-113, ISSN 0195-6086; online ISSN 1533-8665. (C) $\mathbf{2 0 0 4}$ by the Society for the Study of Symbolic Interaction. All rights reserved.

Send requests for permission to reprint to: Rights and Permissions, University of California Press, Journals Division, 2000 Center St., Ste. 303, Berkeley, CA 94704-1223. 
Despite the significance accorded gestural communication in the work of G. $\mathrm{H}$. Mead, kinesics, and communication studies, there remains insufficient appreciation, in my view, for how deeply the bodily centered signifying moment pervades social life. Many contemporary theories uncritically assume that signs are purely conventional, yet such views simply cannot do justice to the broader range of gestural, iconic, and even biological aspects of human signification in their own terms. Hence I outline here my view of how the living gesture touches our deepest signifying nature, the self, and public life more generally. Mead's concept of the generalized other, though a good starting point, needs to be supplemented by a more detailed understanding of body semiotics, one that can bridge the prehistoric world of hunter-gatherers - from whom our present bodies are shaped-with that of contemporary technoculture, in which our present bodies live. ${ }^{1}$

The Greek term phronesis, usually translated as "prudence" or practical knowledge, had an early literal meaning for the area around the heart (phren), including the life-breathing lungs. To say that the heart and lungs are associated with reasonableness seems odd to a modern person knowledgeable about the brain. For we live in the mechanical universe described by Thomas Hobbes in Leviathan, where he stated, "For what is the heart, but a spring; and the nerves, but so many strings." Yet the living, breathing, pulsing, bodily center of gravity makes great sense when one shifts from a conception of knowledge to one of awareness as a basis for reasonableness. For that is what we mean when we say that someone acts "with heart," or "from their gut," namely, that the bodily organs of awareness-of the perceptive practice of the senses, emotions, and imagination-are brought to bear in the moment for interpretation and for acting upon the situation.

In Hans-Georg Gadamer's hermeneutics, phronesis, or practical knowledge, is a commonsense reservoir of experiences and prejudices, of tempered habits that enter into conduct. Gadamer's lengthy debate with Jürgen Habermas concerned whether phronesis was more like what Habermas would later call "communicative rationality" or more a context-specific kind of knowledge, capable of responding with right judgment to a situation (Gadamer 1980).

It seems to me that Gadamer had the more persuasive argument, yet I am claiming that phronesis is something even more than a kind of knowledge. Phronesis is the breathing, palpitating (phren = heart area) bodily awareness of the situation, the spontaneous soul brought to bear on life. It is the living gesture bodied forth in the signifying moment, connecting us with the very conditions out of which the human body evolved into its present condition. It is the living heritage of our hunter-gatherer bodies, evolved to attune themselves to a living and signifying environment.

The human self is an organic sign-complex rooted in socialization processes that include not only cultural values and personal experience but also biological development and in-tempered capacities of the human genome itself. The roots of the human self remain connected to wildness. This wildness is not the antisocial conception of the unconscious Freud proposed, or the antisocial conception of nature that Hobbes earlier elaborated and from which Freud drew. Rather, this wildness within 
derives from socially in-tempered capacities of the human body, in-tempered forms of reasonableness, of sensing and communicative abilities originating in our huntergatherer and even primate and mammalian past (Shepard 1998).

The self goes far deeper than discourse, and the spontaneous self can also do "self-constructing." That, after all, is what living is about. Using your gut sense in practical situations does not mean justifying your ideology, and does not mean some uncanny automatic correct response. It means cultivating a center of gravity stemming from one's passions rather than from one's rational thought and allowing that deeper center of gravity to sense situations and speak freely in the dialogue of mind. A center of gravity rooted in the passions by no means ensures correct conduct but only openness to a broader base of information on which to act. The resources of passionate reasonableness, like rationality, must be cultivated in experience, practiced in felt situations.

Without such cultivation, one has no gut sense on which to act but only some immature infantile needs, perhaps disguised by rationales. Unfortunately, modern civilization has tended to favor precisely such creatures, emotionally infantilized, rationally hyperdeveloped: the spiritless specialists and heartless hedonists to whom Max Weber called attention. That is why Albert Speer commented that when Hitler raved and ranted at meetings he did not necessarily mean what he said, but when he spoke in a cool, calm, and collected manner-rationally-at a meeting, he meant business.

As the philosopher and logician Charles S. Peirce (1931:par. 627) put it more than a century ago, "The mental qualities we most admire in all human beings except our several selves are the maiden's delicacy, the mother's devotion, manly courage, and other inheritances that have come to us from the biped who did not yet speak; while the characters that are most contemptible take their origin in reasoning. ... It is the instincts, the sentiments, that make the substance of the soul. Cognition is only its surface, its locus of contact with what is external to it." Peirce championed rational science, yet acknowledged that in practical conduct there are modes of inference available that go deeper than rational inference.

Sensing situations with one's heart, guts, genitals, or whatever bodily metaphor seems most appropriate provides a far surer guide to the conduct of practical life than a rational approach. The purely rational approach simply cannot sense as much in many everyday situations and has less of a range of information on which to make an inference. Yet the matrix of modern life would deny the spontaneous intelligence of the human body by formatting it to a rational-mechanical system of calculation.

I propose that a cultural template has come to prominence, which I term the mechanical other. We live in a world in which the mechanical other of technoculture has been relentlessly colonizing the inner world of humanity and the outer world of the biosphere. It represents the transformation of Mead's model of the generalized other into one that is anticommunity, antidemocratic, and, most important, antiorganic, having as its purpose the colonization and replacement of those supreme gifts 
of our organic, sensing, and signifying nature by the dictates of the automaton. It is a driving force in social life these days, manifesting in all the aspects of electroculture, from the Internet to $\mathrm{CD}$ burning to television to surveillance to automated encounters .... and on and on.

The mechanical other is more generally a social construction of the rationalmechanical, nominalist worldview of modern life, of the "ghost in the machine" ideology that splits mind into spectral consciousness or social constructions and body into mechanical law. Yet nature and culture form a continuous polarity, not an unbridgeable dichotomy. The self is more than a ghost in the machine, determined by a matrix of social constructions and language conventions. Some of the capacities of the organic, signifying body that make us most human, such as the spontaneous gesture, are precisely what the mechanical other seems intent on deleting. Yet I claim that it may be precisely these deep-rooted abilities for what I term self-originated experience that can ultimately offset automatism (Halton 1995, 2000).

We are live creatures, not word processors, capable of feeling, sensing, and interpreting the world, of opening the doors of perception that reach past the "mind forg'd manacles" of rote habituation, of opening awareness to see the world as it truly is: infinite. And it is the feelings, sensings, images, and gestures that open us to the fullness of the living moment and that best feed the reflective self.

\title{
SIGNS OF SELF-CONSTRUCTION
}

\author{
Make me! You're made, and what a mess! \\ —Children's taunting
}

As sociologists well know, Mead's (1934:13-14) developmental theory of the self involves a progressive internalization of the other, beginning in a "conversation of gestures," through a level of "play" involving specific others, and culminating in a "generalized other," an inner representation of community who is "me" in that internal dialogue of "I" and "me" that comprises the self of self-consciousness.

In Mead's view, it is the internalized attitudes and values of the community and not only a specific role model that mark the fully developed human self. The extent to which some nonhuman animals engage in these internalizing processes seems to me an interesting question for animal researchers to explore and for social theorists to consider. How deep do internalizing processes go? Does mother-infant bonding characteristic of mammals mark the evolutionary beginnings of the proto-self? Do mourning rituals exhibited by elephants, whose brain memory capacities are far greater than those of humans, suggest a proto-self as well?

"Conversation of gestures" is often taken to mean the gestural languages of other animals and an immature developmental level of humans, in which the child has not yet learned how to internalize, or take the role of, the generalized other. Yet this developmental level of the conversation of gestures is not erased by later development but continues as a significant element of the mature generalized other 
in public life. In Gregory Bateson's (1972:614) words: “If ... verbal language were in any sense an evolutionary replacement of communication by means of kinesics and paralanguage, we would expect the old, predominantly iconic systems to have undergone conspicuous decay. Clearly they have not. Rather, the kinesics of men have become richer and more complex, and paralanguage has blossomed side by side with the evolution of verbal language."

The human ability to engage in gestural conversations retains its preconscious animal sensing and emotional communicative origins while yet embedded in the inner representation of social life that is the generalized other, what Mead (1922:246) termed the significant symbol: "The significant symbol is then the gesture, the sign, the word which is addressed to the self when it is addressed to another individual, and is addressed to another, in form to all other individuals, when it is addressed to the self." It strikes me as interesting that in this definition, Mead stresses addressed. For the gestural level of human public life is not always conscious, though it plays a significant role in the comprehension of utterances. Hence gestures may be "addressed" to others and to one's self-meeting Mead's definition of a significant symbol-without one necessarily being aware of what the gesture, or body language, is communicating. But they might also be more unconsciously animal as well. It is not a question of an either/or dichotomy, for even while gesturing the significant symbols of the human animal, we remain primates and mammals conversing through gestures. That too is part of human nature; without the preverbal primate and mammal within, we are less than fully human. Stated differently, wildness is not only without but within the very structure of the human brain and body as well. Antonio Damasio $(1994,1999,2003)$ argues that emotions are not only crucial for evolutionary survival, but also for our ability to think. Rational thought is biologically dependent on more basic emotional capacities for optimal functioning.

Mead's theory of the generalized other throws an interesting psychological perspective on Aristotle's view that man is by nature zoon politikon, a political animal. Becoming self-conscious in Mead's general theory involves establishing an internal polis, or community. In contrast, Freud's model of socialization involves establishing an internal family through the resolution of the Oedipus complex. Just as Hobbes reversed Aristotle's conception of human nature from "public animal" to one of a privatized, antisocial, maximizing competitor, Freud's model represents the privatization of development to a family imago erected over a purely self-gratifying unconscious, a stimulus-response pleasure machine. Aristotle's internalized polis-Mead's generalized other-becomes Hobbes's internalized family feud in Freud's model, in which the it, das Es, as Freud termed the unconscious in German vernacular- "id" in English translation-is the savage state of nature within us, domesticated by the internalized family imago.

Freud draws attention to the ways that a child internalizes the most significant objects in the environment, the parents-an insight sorely lacking in Mead's theory, which does not single out the parents for special developmental attention. Freud's overly inward theory could have broadened Mead's conception of the social, just as 
Mead's model of development could have profited from Freud's attention to the significance of inner mother and father representations. Freud's understanding of socialization rests problematically on Hobbes's reversal of Aristotle's conception of human nature to one of antisocial competitive struggle. Perhaps Freud's Oedipal family corresponds more to Mead's developmental level of "play," involving the internalization of specific others.

Yet nature and nurture remain irreconcilably quite different in the two models: Freud's it, or id, is rooted in Hobbes's fiction of antisocial individualism, of a state of nature incapable of social signification, and the I, or ego, is the nurtured resolution of the Oedipal conflict: a symbiotic triadic symbol relating boy to mother through identification with father. This basis for the I, or self, and for symbolic consciousness, is a social fiction, and all social relations are analytically reducible to their disguised dyadic underpinnings. Despite his appreciation for the symbolic in human affairs, Freud believed symbolic behavior would be ultimately understandable as stimulus-response physiology. Hence triadic symbolic interaction is reducible to dyadic physiology in his metapsychology.

Freud's theory reveals the social fiction of nominalism, and in Hobbes and Descartes we see the modern privatization of the self, in which the real social relations that constitute zoon politikon are treated as secondary accretions (MacIntyre 1981). Yet the short, nasty, brutish life of nature claimed by Hobbes actually corresponds to the reverse, to the changes brought about by the institutions of civilization (Sahlins 1973).

By contrast, Mead and the other pragmatists opened the way to conceive nature as social and significative and nurture as both natural and real. With a continuity of nature and nurture, one can say that nature produces some social constructions, such as mother-infant bonding, bodies them forth in human practices whose locus remains bodily purposes, however attenuated those purposes may become (Holler 2002; Montagu 1978).

What are the machine systems now relentlessly expanding their global grip, if not bodily purposes run amuck, of the automatic and rational aspects of our brains, overextended? Zoon automaton - automatic animal-is the source of the modern fiction of the id, relentlessly maximizing its private gain. Yet zoon automaton remains a social construction of human nature, of Aristotle's zoon politikon, even though it has the extinction of human nature as its unacknowledged telos. Those empathic, spontaneous, sensing capacities of the political animal are dangerous to that social construction which is automatic animal.

The gestural level of communication ought to be the bodying forth of communication, even as speech is the mouthing of it. I have a book at home titled Italian Without Words, which playfully suggests that one can engage in a full public life in Italy through the range of gestures one exhibits (if you violently disagree with this idea, imagine the gesture you could respond with to address your disagreement). Since the time of Mead's writing, kinesics has shown how deeply body language is embedded in communication.

Such public gestures are more than brute referential pointings, more than mere 
linguistic utterances. They give lie to the erroneous idea that public life is merely linguistic utterance, found in recent pseudopragmatists such as Rorty or Habermas. For even "linguistic utterance" itself is more than linguistic utterance, involving deep gestural and emotional capacities (Halton 1995:226-34). Consider, for example, the neurologist Oliver Sacks's discussion of patients with aphasia, unable to comprehend the meanings of words. Often it took some time to realize their deficit, because they understood the nonverbal tone and gesture so well:

\begin{abstract}
A ... speech—natural speech—does not consist of words alone, nor ... propositions alone. It consists of utterance-an uttering-forth of one's whole meaning with one's whole being - the understanding of which involves infinitely more than mere word-recognition. And this was the clue to aphasiacs' understanding, even when they might be wholly uncomprehending of words as such. For though the words, the verbal constructions, per se, might convey nothing, spoken language is normally suffused with "tone," embedded in an expressiveness which transcends the verbal - and it is precisely this expressiveness, so deep, so various, so complex, so subtle, which is perfectly preserved in aphasia, though understanding of words be destroyed. Preserved-and often more: preternaturally enhanced.

Thus the feeling I sometimes have-which all of us who work closely with aphasiacs have- that one cannot lie to an aphasiac. He cannot grasp your words, and so cannot be deceived by them; but what he grasps he grasps with infallible precision, namely the expression that goes with the words, that total, spontaneous, involuntary expressiveness which can never be simulated or faked, as words alone can, all too easily....
\end{abstract}

That is why they laughed at the President's speech. (Sacks 1987:81)

Many thinkers identified with postmodernism do not admit natural aspects of the self, despite the facts to which case studies such as Sacks's or the work of Damasio call attention. Yet admitting that we are born with a temperament or biosocial needs does not disallow possibilities for major change and even transformations of personality. The self is composed of many ingredients that are not even personal: our ancestors have a way of finding expression in us, and there are mammal characteristics, not even specific to humans, that nevertheless are crucial for the development of the human self, such as play, mother-infant bonding and separation, and REM dreaming. Consider the spontaneous smile or sob, as Damasio describes the process:

A ... spontaneous smile that comes from genuine delight or the spontaneous sobbing that is caused by grief are executed by brain structures located deep in the brain stem under the control of the cingulate region. We have no means of exerting direct voluntary control over the neural processes in those regions. We are about as effective at stopping an emotion as we are about stopping a sneeze. (1999:48-49)

These biosocial characteristics remain essentials of the self, despite recent claims that there are no essentials, no human nature, no universals, no reality to the self, and that it is simply a social construction. One reads this in authors such as Rorty, 
who conveys the assumption in quasi-easygoing language. "It's socialization all the way down," he says, reciting a version of socialization as a kind of passive indoctrination into rote conventions, a view that no social science undergraduate could get away with. Rorty denies the place of biology, experience, extra-conventional meaning, purposiveness, and pragmatic consequences in human conduct: all crucial to the four original pragmatists. It is why I call Rorty an antipragmatist, a fragmatist (Halton 1995:219-46).

Though Rorty frames his theory in terms of conversation, it is the antithesis of that older Socratic dialogical form of discourse. For Socrates, the purpose of dialogue is a mutual quest for truth, and philosophy is the loving pursuit of wisdom. Rorty abandoned the love of wisdom, abandoned philosophy, saying that it is based on a false conception of a "final vocabulary," when all there is are conventions and contingenciesidiosyncratic historical products rather than fallible truths (Rorty 1989:96-97). This amounts to a denial of the ideas of inquiry in Peirce, Dewey, and Mead.

Rorty also undoes dialogue, as understood by Peirce, Dewey, and Mead. For them, all thought is an internal dialogue, and all dialogue, the communicative flow of signs, occurs in a context of normative inquiry. The earlier pragmatists saw dialogue - inner and outer-as involving the possibility of self-correction. Rorty does not; dialogue is simply the enacting of conventions and contingent redescriptions. Far from providing a thoroughgoing account of meaning, Rorty's theory seems to me to coalesce with that of the ideal consumer of contemporary consumption culture, limited to conventional conformism or contingent impulse, purposely essential-less, essentially purposeless.

Peirce, the originator of pragmatism, began the development of its ideas in a series of essays that destroyed Cartesian foundationalism. Rorty excludes Peirce from his consideration, dispensing him as the mere originator of the name "pragmatism," ignorant of the significance of Peirce's fallibilism and its implications for final vocabularies. Peirce is far closer to the spirit of Socrates than is Rorty. Rorty denies what Socrates stands for-the loving pursuit of wisdom, or philosophia.

Or consider the psychologist Kenneth Gergen, who says in his book, The Saturated Self:

Thus, interest in "true identities" and "actual characteristics" of persons can be replaced by concern with the perspectives in which they are constructed. It is in this context that many scholars have become deeply interested in people's commonsense beliefs about themselves and others, and the impact of these beliefs on their actions.... In all such cases the attention turns from the nature of real love, intelligence, aging, child development, and so on to show how it is constructed or represented in the culture. For good or ill, it is the individual as socially constructed that finally informs people's patterns of action. And in the end, there is no means of moving past the constructions to locate the real. (1991:146)

Clearly selves are constructed in social contexts and relationships, the analysis of which is the stuff of which the social sciences are made. But many thinkers take this fact of social construction to mean that social life is necessarily unreal. The good 
news of the postmodern gospel as proclaimed by Baudrillard, Derrida, Lyotard, Rorty, and Gergen is that the self is relational; the bad news is that the relations are unreal. All that can be loved is a mere fiction in this damaged view of life, which excludes the possibility that the narrative of social life can also be real. Though admittedly there are exceptions, such conceptions of the self and of signification as these figures hold represents a cultural and intellectual expression of the new phase of alienation and automatism under way in global consumption culture, in my view. It is more the embrace of the pathology rather than a critical understanding of it, and Gergen provides a clear example of why.

Gergen discussed Mead in his earlier social-psych work but strangely ignores him in his writing on what he terms the "relational" self, despite the fact that Mead developed a relational theory of the self. Gergen's postmodern self is based in neoSaussurean premises that all meaning is conventional or contingent, a nominalist assumption that is not only too narrow an understanding of signs, but in my opinion false. Mead's deeper conception of self, in transaction with its community without and within - that is, relational-allows that the self is a live experiencing creature, in contrast to Gergen's conception of self as a creature of habit, reducible to "social construction," to "representation" considered as limited to convention. Mead's model allows for social construction, as the term is being used, but it allows further that nature and experience may be ingredient in social constructing.

Gergen is incapable of delivering a rich understanding of the living self because he is weighed down with inadequate, obsolete Saussurean semiotics. The shadow of Saussure's anorexic understanding of signs is now an unconscious uncritical assumption not only of Gergen, or Rorty, but of the postmodern turn generally (Halton 1986:43-70, 95-105; 1995:79-119). Peirce and Mead allow signs to do many more things than the Saussurean tradition does: in addition to conventional meaning, signs touch experience, they are not limited to a conventional disguise for it, abstracted from it. Human conduct is semeiosis - sign-process - in the pragmatist tradition.

The self is much more than a matrix of societal construction, it is a construction worker, actively constructing itself while participating in the larger organic and cultural construction and reconstruction that is society and that is the medium for selfdevelopment. Its "bricks" and its body are signs, representations, considered not as some inhumanoid Saussurean matrix but as living semeiosis: the practice of life is a practice of signs. When Gergen claims, "And in the end, there is no means of moving past the constructions to locate the real," he reveals how little he knows about signs - the very stuff of which constructions are made.

Reality, far from being unreachable—as the postmodern litany would have it—is itself of the nature of a sign: the veil of maya that is illusion is also the construction itself. Hence the idea that it must be either reality or social construction is a false dichotomy.

The originator of pragmatism and of semiotics, Peirce, defined reality as that sign which will determine social construction to itself in the long run, through the community of interpretation it engenders. This view is easier to see in natural science perhaps but gets more complicated in social science, where some conventions are 
not necessarily "true" or "false." Yet even there it has application, casting a view of social construction as a purposive sign-practice ingredient in the ongoing making of the good life.

Unreal cultural systems can produce unreal selves. Indeed, that is a system requirement of contemporary consumption culture in my view. Yet reality can also construct real selves, capable of feeling, sensing, experiencing, thinking, and learning their way in the world. But a real self cannot live from the neck up, as a mental convention, as Gergen's selves do, because living from the neck up is the alienation from the vital sources of self, the bodily passions through which we attune to real life. Those sensing, imagining, revering, and attuning passions were crucial to the physical evolution of the anatomically modern humans who walked their way out of the ice age. This emergent human was neither a Hobbesian psychopathic brute, nor some antisocial expression of the Freudian "primal horde," nor a creature whose consciousness was merely composed of arbitrary conventions. The aboriginal evolutionary social construction of the human body issued forth through its deep, practiced attunement to the signs of surrounding life. And despite twelve thousand years of agriculture and civilization, we still inhabit these hunter-gatherer bodies, made to attune to the myriad signs of surrounding life, made to love the fantastic reality of life.

Indeed, animism, or the relation, as David Abram (1997) has happily put it, of the human to the greater-than-human, is the consciousness of the original social construction of the self, that of the hunter-gatherer. I claim that there is good reason to suspect that the original generalized other was not solely human but also involved a relationship rooted in participating awareness of the drama of life. The animals and plants constituted a forest of symbols with practical and religious significance, and requiring intense study and rumination over the gestures they communicated. The animals, plants, and surrounding landscapes peopled the original generalized other to an extent that civilized consciousness, anthropocentrically enclosed in a human fabricated world, can scarcely appreciate.

Though many of our cognitive beliefs may have been developed in civilized societies and their cultural conventions, the self reaches far deeper than this. It reaches deep into the human body, and that body was refined over many tens of thousands of years of hunter-gatherer life and developed over an even longer period of hominid, primate, and mammalian evolution. As the ethnographic record demonstrates, hunter-gatherer societies tend to be deeply ritually based and must continually attune themselves to the surrounding environment on which they depend.

Animism, usually described as the worship of spirits in trees and stones, and so on, is more understandable as the reverential attunement of the human to the greaterthan-human. And that greater-than-human is the living environment in which the sacred play of consumption, of hunting and gathering, occurs. It is a sacred game of life-forms consuming and being consumed by each other, in which the human gathering or hunting might just as well be prey as predator. As an Amazonian Amahuaca man put it in describing the dangers of using bird calls to capture the tinamou bird: 
"I backed up between the buttresses of a big tree where the ground could be seen for a good distance in front of me, and I started calling the birds to me. You know that it is dangerous to call the tinamou without the protection of a big tree. The jaguar sometimes comes in to answer the call! The tinamou is also his favorite bird" (quoted in Abram 1997:143).

This man reveals a deep awareness of the place of attunement and entrancement in the drama of the hunt: he must be so immersed in the role of the tinamou that it believes his call is that of a tinamou. But he must also identify with the tinamou as prey, aware that the jaguar attunes to its call, and would happily consume it or him. The more aware of these life-signs surrounding him, the better he can participate in the entrancement of the hunt. His generalized other is literally a forest of living symbols. But that very entrancement must have self-critical protections as part of the awareness.

In the form in which it evolved into its physical being, such a being could not countenance burning up the forests of the earth and emptying the oceans simply for commodity gain, as we are now doing, for that being evolved in a greater-thanhuman world to which it needed to attune itself to live. Only by relieving it of its original awareness and attunements could it reach a state in which killing-gain could replace its habitat-relation. Such relief was originally provided by agriculturally based civilization, its bureaucratic institutions and specialization of labor, later radically amplified by the mechanical-scientific worldview, now perfecting the substitution of real life by virtual "living," mistakenly called virtual reality (Halton forthcoming).

Such a view not only can now countenance burning mother forest, who originally gave us life, but also can view the genuine ripe fruits of civilizations, of Mona Lisa and Moby-Dick, as one cognitive scientist told me, as mere rules and conventions, in effect, replaceable parts in a replaceable universe, simply information. This is rational madness, and is indeed what has been happening. We are burning all of it: the wisdom of the past, the variescence of the living earth, burning it in utter greed and hubris.

Scientific materialism is rooted in a conception of the universe as basically composed of dead matter in motion, out of which life springs by chance, yet the word itself (Latin, materia) springs from the life-giving capacity that defines a mother, and by analogy, the shoot-producing trunk of a tree, "-mater being the trunk, which produces the shoots; mater, therefore, is here a transferred use of mater, mother" (Partridge 1958:387). Like many other inversions produced in modern consciousness and traceable etymologically, the dead matter universe of materialism literally derives from the life-giving mother-tree. Behind modern materialism, it would seem, stands the shadow of what the Ba-mbuti pygmies have called for forty thousand years Mother Forest.

Sedentary, contemporary globalizing civilizational consciousness seems bent on achieving autogenocide, and one of its most powerful banners for this process is what it likes to call "science." It prides itself by saying that it is scientific, and usually 
means by this that it is beyond ideology, beyond moral obligations, beyond basic criticisms from outside of its institutional box: it is, in brief, Nietzsche's Übermensch, in a white lab coat. Yet contemporary sci-tech, I claim, functions as an ideological projection of a worldview that can be termed the mechanical other.

And the way this colonizing mechanical other typically targets the self is precisely through the fantastic appearances that will seduce our hunter-gatherer bodies. Marx's "fetishism of commodities" is indeed an apt term for this process. When the mad scientist Rotwang in Fritz Lang's 1926 classic film, Metropolis, creates the first robot, he clothes her in seductive flesh and replaces the mothering Maria and her message of love that she preaches to the workers with this facsimile sex machine and its message of hate. Lang was deeply aware of how the rational-mechanical system of modern life must cover itself in the appearance of flesh, of "all that is human," if it is to relieve humanity of self-originated experience by seducing it into machineoriginated experience.

Modern materialist civilization, rooted in the bifurcated thought-versus-thing world of nominalism, represents a complete inversion of the bodily awarenesscentered, environmentally attuned, reverential self through which we became human. Indeed, from my perspective it is the social construction of a vast, mechanical, antibody whose goal is to eradicate fully incarnate human being and variescent, spontaneous life: a virtualized, commodified world with no more vital experience, no real love, no pullulating dream-world, but only isolate brain-processors, themselves replaceable (Mumford 1967, 1970).

Do you believe in your heart of hearts, dear reader, that love is a fiction and only convention and contingency are "real"? Try to imagine how love might be a reality. Try to imagine, as figures as diverse as Peirce, Dostoyevsky, and Melville did, how the social construction of society might even involve such love, as genuine general relation, transcending convention and contingency (Halton 1986). "Evolutionary love," as Peirce (1931) called it in an essay of that title, is such a genuine general relation. Otherwise, sooner or later, pluralistic dressing or not, one is reduced to the old Hobbes-World nominalism of contingent nature and conventional culture, in which all that can be loved is a mere, unreal fiction.

In an interview, Kenneth Gergen could literally not even admit that he loved his wife, because it clashed with his ideological social constructionism. It wasn't that he didn't love her-in the everyday sense-but that he couldn't bring himself to use the word love because of his ideological belief in social construction as mere conventional determination of the self. To this his wife, Mary Gergen, also a psychologist, replied: “Look, when I ask you whether you love me, don't go through these tortuous questions of what's really real about love and how you'd know. Just say the words meaningfully and I'd be a lot better off" (Stephens 1992:40).

When love-or even feigned love-becomes a word to be avoided, it would seem that what William James termed vicious intellectualism is at work. Gergen, in the name of freeing the self, actually confines it to a much narrower position.

Why consider essentialism then? My answer is that antiessentialists falsely 
assume, like their essentialist opponents, that essences are not also signs. This is usually because antiessentialists are themselves passively indoctrinated into the Saussurean theory of signs as limited to conventions. But essences are iconic signs that signify their own identity. And real selves and works possess identity, their signifying essence. By this, I mean that essence is communicative. A convincing piece of music, in this sense, has its own identity, its own being, by virtue of what it is and not only by its difference from everything else. The same holds true for a self. And the reality of the healthy human self is that it is a multiple personality order-in contrast to the pathology of multiple personality disorder. Yet how the multiple self that comprises one holds together is often quite mysterious.

As I see it, there is also an element of brute, nondialogical otherness in experience, which is not at all "constructed" by the self, yet which tempers it. And the feeling, sensing, gesturing, and even speaking self, is not indigenously a mere passive "social construction" brainwashed by some social matrix-though clearly that "automatic animal," reduced to glorying in "life-support" entertainment commodities seems to be a deliberate goal of contemporary technoconsumption culture. Yet indigenously the living self is a construction worker, actively involved in its own social construction.

Many animals have the ability to sense the specific other as other. For example, a recent documentary on animal consciousness and the people who interacted with animals on the animals' own terms, such as a grizzly bear trainer and the anthropologist Jane Goodall, showed how such full communicative involvement with the animals allowed these people to go far beyond lab researchers in understanding, because they allowed their feelings in the interactions as valid data.

The trainer described his play with the grizzly. At one point as the nine-foot-tall, two-thousand-pound bear has most of its mouth around the trainer's head, you can hear him command: "No teeth!" And he told of how the bear will sometimes test limits, for example, of how much force it can use, and will be looking out of the corner of its eye to gauge his response. This seems to me a crucial component of play fighting (and play in general)—sensing the other through the limits of the interaction. In this case, the imperative voice gave the limit, where an interrogative voice would have spelled out to the bear: Free meal!

I had the opportunity, while attending the Society for the Advancement of American Philosophy meeting in Las Vegas, to speak with a tiger and bird trainer who was performing down the hall from the meeting. Joe Kratwohl told me how he was once rehearsing a scene for a film with one of his tigers, how he initiated its attack sequence by feigning running away. The tiger was supposed to catch him and muzzle the right and left sides of his neck and then stomach, but when it went from left side of stomach to right side, Kratwohl could feel its teeth emerging and beginning to shift to biting instead of muzzling. He described the pursuit trajectory of a tiger as "chase, tackle, bite, eat," a trajectory that can only be broken by superior force. Sensing the teeth-the instinctive bite phase that was not supposed to be engagedKratwohl immediately grabbed the fifteen-hundred-pound tiger around the neck in 
a choke hold while ramming the base of his hand as hard as possible into its face, stunning it, while he then muscled it down on its side. This was a conversation of gestures with a vital purpose: Kratwohl's very survival. The tiger then got up and walked away in fear, and minutes later, when Kratwohl asked it if it wanted to come over to him, he told me the tiger, still fearful, "went over to some nearby bushes as if to say, 'No thank you, think I'll just smell these bushes over here,'” gesturing submission.

Kratwohl said the tigers he trains must believe that he is more powerful and that his domination over them alone is what commands their obedience to him. "The day that I cannot command that obedience and the sense that I am more powerful is the day that I will no longer be in that cage." His story illustrates that the most important animal for the animal trainer to train is himself or herself. The trainer's own instinctive responses and bodily attunement are crucial for the live eat-or-be-eaten dynamics of such situations, and must be available through constant practice and awareness. Such is how our originating ancestors became human, through intense awareness to the plants and animals and terrain, and to themselves. There are no do-overs in this conversation of gestures: Thinking and symbolic verbalizing would only amount to the message "Eat me."

\section{IDEALS AND PUBLIC VIRTUE: MEGA-REFLEX-ARC-AMERICA}

Much in contemporary life in America divests Americans not only of public spaces, but of the free range of public gestures that are ingredient in public life. Consumption dictates usurp free association and often impose standards of conduct designed to promote consumption and to devalue nonconsuming conduct and rights of citizenship for public assembly (Halton 2000). And these problems are all exacerbated in the automatic culture of America, which has been busily replacing for some time now the practice and institutions of democracy with an ever-expanding mega-reflex-arc.

In his 1896 paper on the reflex-arc concept, Dewey showed how the stimulusresponse model falsely assumed the stimulus to be a raw, unconditioned starting point, instead of itself the response to prior social stimuli-cycles, not arcs. Three years later, in chapter 7 of his groundbreaking book, The Interpretation of Dreams, Freud used the same reflex-arc concept Dewey had criticized as the metapsychological basis of his theory. He would have done well to have read Dewey's paper.

The reflex-arc model reduces conduct to conditioning, to a sensationalist model of psychology ultimately based on pleasure and pain. It excludes the spontaneous dimension of conduct, and the possibility of autonomy-of self-controlled conduct oriented by general ends rather than by discrete sensations of pleasure and pain. It forecloses the genuinely triadic nature of signification. It takes the perilous out of experience through its foreclosure of the conditioned response.

Dewey's philosophy of conduct provided an alternative to these shortcomings, and remains a critical alternative to many contemporary outlooks on social life and meaning that are unable to consider conduct and experience as communicative in 
their own right. Yet Dewey's center of gravity was in making knowledge-securedthrough-inquiry the outcome of practice and a basis for social reconstruction. He sought to extend the model of theoretical scientific inquiry to practical life in the name of pragmatic "instrumentalism." But is "knowledge" even the right term for that goal? Is awareness knowledge? Is beauty? Is the practical wisdom of phronesis? Or am I quibbling?

In short, is "knowledge" sufficient for the conduct of life, even when considered in Dewey's terms as "habits of conduct," or does the model of scientific inquiry-no matter how broadly conceived-remain too restrictive for the practice of public life? In my opinion it does remain too restrictive, and represents one of the failings of Dewey's optimism. He did not fully appreciate how emotions form the prime vehicle for the arts of the human body itself, in its social practices. Living from the passions in everyday life is a surer guide for practical conduct than the model of scientific inquiry, though still fallible. The aim of obliterating the divide between scientific theory and the practice of life in the name of democracy failed to consider that life bears deeper forms of reasonableness than the model of inquiry can encompass, and that critical intelligence remains embedded in these other forms of intelligence.

Living life by the ideals of inquiry and logic is like dissecting a whale to understand Moby Dick. Living life attuned to its rhythms is like rolling in the waves with the white whale itself, alive to the perilous presence of "the ungraspable phantom of life." Surely we live life with logic and rationality, but we live life from our bodies, whose feeling, sensing, communicating capacities go far deeper than rationality alone, in my opinion, and form a better basis for conscience. The rational-mechanical system of modern life assumes a progressively maximizing rational standard of reason, one Max Weber both saw and yet was himself a symptom of. He was unable to see that a dichotomy of the rational and the nonrational is false, that reason is more than rationality, and that optimal rationality requires nonrational reasonableness. Yet the rational is and must be anchored by the deeper extrarational reasonableness of the feeling, sensing self to function optimally.

A new balance of reasonableness is called for, a new kind of civilization that can reattune to those extrarational bodily capacities as essential for reasonableness (Montagu and Matson 1983). Those balancing attributes of human nature remain embedded in the human body. As Nietzsche said in Beyond Good and Evil, "To be mistaken about the rhythm of a sentence is to be mistaken about the very meaning of that sentence." Or more succinctly, in the words of Irving Mills and Duke Ellington: "It Don't Mean a Thing (If It Ain't Got That Swing)!" A nation cannot make valid democratic interpretations for long if it does not practice the autonomy required for democracy. If it shifts to practicing automatic culture instead of autonomy, it quickly becomes as "democratic" as the former German Democratic Republic.

That, unfortunately, seems to be the state of Reflex-Arc-Macro-Soft-America today: auto-conditioned mass individuals busily pushing the various "food" buttons of their cage-money, machines, and all the powers of Mighty Mammon-ready to stimulate-response themselves without limit unto death. What is the symbol of Las 
Vegas in contemporary American culture if not the mirror and Mecca of MegaReflex-Arc-America, the total addiction environment as desirable destination? It is one visible symbol of the "invisible dictator" of modern life, the rational, calculating machine covered in fantastic "flesh." In the fantastic entertainment complex one sees the reintroduction of animism's relation of human to greater-than-human but in perverted form: with all the natural life of the desert shut out of view of the magic casino-enclosed environments, the greater-than-human now appears as the Megamachine itself.

The cultural symbol of "Las Vegas" personifies the broader entertainment complex, which functions as a cryptoreligious symbol of the mechanical other, part of the larger body-mind-soul-numbing consumption culture at work, whose system requirements seem to involve disabling the emotions by providing virtual substitutes. The entire entertainment complex, especially including its pervasive kitsch, functions to give the rational-mechanical system the appearance of a human face. In that guise the mechanical other more easily infiltrates the human self, toward an end of rendering it the "software" of the system. Through its ever more pervasive advertising - which now exposes Americans to three and a half thousand ads per day-the system indoctrinates people to identify commercial desires as their own, materialistic fantasies as the dreams of which their selves are made. Welcome to the matrix!

The end result is a consumption-addicted, increasingly obese population of couch potatoes pushing the stimulus-response buttons of their consumption cages, ever more emptied of their real lives as feeling, passionate beings, ever more removed from living in truth by consumption kitsch. Advertising is the opiate of the people. Democracy cannot survive for long by living on automatic.

The life of democracy requires critical autonomy. I am exercising my critical autonomy in criticizing my society for its loss of critical autonomy. I was also pushing buttons on my computer writing these words, so I do not claim to be completely free from the tentacles of the reflex-arc: and who can, especially if you have children in this culture.

But it is pathological: pathological materialist excess. Take the obesity epidemic that began to spread in the 1990s, as an article in the Journal of the American Medical Association (Mokdad et al. 1999) put it, "with the speed and dispersion characteristic of a communicable disease epidemic." For an epidemic of the public vice of gluttony to emerge across all age, race, class, and gender lines this quickly, something obviously has to be eating Americans. In my opinion it is nothing less than pathological material consumption compulsions masking inner emptiness and depression. Thus, consumptive America, pushing the buttons that anesthetize, is the Mega-Reflex-Arc auto-conditioning its tired, isolated mass self.

Now antibiotics have been abused by the meat industry in ways humans are beginning to pay for. But who would have thought that Americans would conduct biological warfare on ourselves, using fat as the weapon! But effective weapon it is, a very good weapon to lower awareness, to keep the potato on the couch, reduced to 
mentalized button pushing through the mirage of "eat me" images and commercial soul seductions. The Couch Potato is perhaps the penultimate perverse perfection of the sedentary creature brought into being through agriculture and civilization.

What better way to alienate people from the human body, the very temple of our signifying nature, than to encase us in it. The obesity epidemic is one indicator of larger anticorporeal purposes at work, for Americans have also developed similar patterns of alienation from the body in other domains. Home cooking less while eating more, the automated American is also underslept and underwalked, overworked and overspent, for these deprivations enhance compliance and reduced awareness. Aware, autonomous citizens do not possess the compliance capabilities of unaware, automatic consumers, "couched" in the hypnotic visage of the electroTele-Medusa.

The postdemocratic consumption creature is the antithesis of the democratic citizen, capable of phronesis. Automated, unaware consciousness, conditioned by the stimulus-response/pleasure-pain matrix, is intrinsically depressing. Such pathology can be addressed as gestures of alienation, of an inner world colonized by the mechanical other and turned to serve largely as its self-replicating software.

This introduces one of the great challenges we face today, it seems to me. How might the all-powerful, globalizing Corporate Empire be transformed to face and attune itself to organic limitations-limitations of the earth's bounty, of global human population, of the biosphere itself, of self-responsible societies and spontaneous selves? If it cannot, then there is nothing more to be said, and it should not take more than about twenty years for this globally, electronically, virally, economically, and spiritually interconnected world to collapse from its excesses as suddenly as the World Trade Center did in a single day. But to deny that it is also a human entity, however dehumanizing, seems to me to surrender to the myth of the machine as some alien thing that is not also a human social construction. That is an alienated view of the mechanical other, in my opinion. No matter how dehumanizing, corporations and machines remain human social organizations that ought to be means, not ends, of life.

Awareness, no matter how painful the reality of which one becomes aware, is intrinsically satisfying, and is rooted in self-originated experience. More awareness is what Americans need, especially a general arousal of the visceral awareness that democracy itself has also been under siege from within, lulled into the false security that technomachines could provide security, happiness, and a life. Wild entrancement taps deeper into our bodies, and advertising only wishes it could really go there. But it can't. It must honor its capitalist stimulus-response mechanical outlook, its addictive hook of virtual entrancement and simulated life. Fullbodied awareness, rooted in self-originated experience and the purposes it engenders, can provide a means to democratic life. Consumption itself, to be healthy, must be rooted in acts of awareness and not of dependency, seduction, and addiction. 


\section{PUBLIC VIRTUES AND GROUP IMPROVISATIONS}

You see, there's such a thing as a feeling tone.... And if you don't have this, baby, you've had it.

- Terkel 1967

Music is language of the emotions; it is a test of life.... Everyone reacts to music in a different way and everyone should be able to make it on his own-play and write the music the way he feels it. If he is going to be really great, he must learn to be himself.

—Mingus 1961

Is the individual the ultimate source of ethics? Perhaps the answer is yes, if meant as focal point of ultimate responsibility. But there are also public virtues and group improvisations not reducible to individuals per se. Both social conventions and public virtues can be sources of moral behavior, the morality of the former consisting in the customs, norms, and ideals of conduct, the morality of the latter consisting in the living act itself. I distinguish the virtuous public act from ideal conduct because the character of the virtuous act itself is the source of the morality rather than its conformity to an ideal of conduct: it primarily bodies forth its own end and is only secondarily a means to a good end. In this sense a virtuous act involves spontaneous creative intelligence in order to sense the situation and act rightly.

Spontaneous conduct is more than impulsivity, which is a blind giving in to the moment as a kind of response to a stimulus. In this, impulsivity, like a purely conditioned response, lacks autonomy. In Mega-Reflex-Arc-America, consumption dictates that the two together-the impulsive, yet conditioned, response-form the ideal consumer, conditioned to conform to conventional stimuli. By contrast, spontaneity means being able to act freely in the moment, and is in this sense a culmination of practice — of self-originated experience-rather than raw starting point.

Many people think that musical improvisation is just letting go and allowing whatever randomly pops out to pop out. In the 1940s and 1950s avant-garde aleatory (meaning chance) music of John Cage and others, and later, in some of the more extreme elements of avant-garde jazz in the 1960s, this approach was pursued as a means of freedom.

But it turned out to be a cage, not only in music. You can't make music that way, by blind impulsiveness, only sound results. For even the ear itself requires a past in order to make the present intelligible: the fantasy of Cartesian immediate intuitive self-consciousness that came to dominate the avant-garde in the twentieth century was a mirage: the past cannot be completely expunged without expunging the expunger. This music was a cultural indicator of the failure of nominalism, of its collapse of the signifying moment into the fiction of the stimulus-response reflex-arc.

The dyadic stimulus-response ideal of modern materialism is a fiction that must ignore the reality of the triadic sign that constitutes the signifying moment. The signifying moment involves its past, its body and soul so to speak, bodied forth in the present in intelligible communication addressed to a future other, to an interpreting 
sign. It may be a "conversation of gestures" with the other, or it may be a "significant symbol" addressed to the generalized other without or within, or it may be both.

It is that element of signification that pours forth, bodies forth, as phronesis, the living involvement of the self with the situation in which it is engaged. My terminology may draw heavily here from the world of semiotics, yet the signifying moment could also be described as the world of the hunter-gatherer, immersed through bodily awareness in sensing the drama of life in which he or she is participating, live to the moment. Yet again, the signifying moment could be described as improvisation.

Improvisation is and must be a culmination of a practice, a practice that in the case of music puts the craft of the instrument and the music in the performer's hands or tongue, in the body and soul so that it can be born anew in the making of the music. Consider, for the moment, Ludwig Wittgenstein's claim from his book, Tractatus Logico-Philosophicus, that "the world is all that is the case" ("Die Welt ist alles was die Fall ist"). And in the conclusion he stated: "What can be said at all can be said clearly, and what we cannot we must pass over in silence." This is the voice of tragic, overweening rationalism, which would silence, not only fallibility, but preconscious sensibility and gestural and figurative communication.

Just which world is "all that is the case"? The physical things-go-bump world? Or the world of thought? Or the infinite imaginary worlds: worlds of dreams, the world of what Blake termed the Poetic Imagination, mathematical worlds? If early Wittgenstein thought only the denotative thing-world is the case, he was plainly wrong, in my opinion.

We can talk about things without having to talk about them picture perfectly. If Wittgenstein only meant to say, "put up or shut up," that is, be perfectly clear or be silent, even then, he expressed it in a mystical-sounding but obscurantist way. Yet I thought he meant more, that there is a "picture theory of reality" philosophers are limited to, and that the more ultimate concerns of ethics and aesthetics lie beyond this. If that is his case, it remains an utterly anorexic conception of ethics and aesthetics, and perhaps he saw past it in his turn to "language games" in his later work.

The ethical, which the ancient Greeks saw as the public realm of speech and action, is diabolically banished to the private realm of silence in Wittgenstein's early "final solution" (his term). Yet as Thomas Mann's Mephistopheles puts it in Dr. Faustus: "That is the secret delight and security of hell, that it is not to be informed on, that it is protected from speech, that it just is, but cannot be public in the newspaper, be brought by word to any critical knowledge." In this sense early Wittgenstein was another manifestation of the privatizing of virtue in modern culture, and of the forcing of signification into logico-reductive modes.

Concerning that which cannot be said clearly having to be passed over in silence, one can sing for starters, and paint and dance and engage in the myriad other forms of communication that can express the extralinguistic. In science one can hypothesize, which is the form of inference Peirce termed "abductive," and which is a logical form of extrarational conjecture. Or to return to the case of improvisation in music, 
the musical object so improvised is precisely that in which new possibilities are constantly being discovered by the musician in attunement with the ongoing music. In group improvisation that attunement to the groove - the feel of the rhythm - and to the musical voices of the other musicians is all the more crucial.

This empathic listening and musical dialoguing is all about speaking clearly-not by mere words, but in and through the conversation of musical gestures. Extralinguistic musical gestures "speak" the soul, whereas "talking about music is like dancing about architecture," as Thelonius Monk once said to quiet a critic's question. In ensemble playing, new possibilities are being codiscovered in the creative spontaneous intelligence of the ensemble itself through self-originated experience.

The signifying moment speaks itself.

And in the origins of jazz, the living gesture spoke itself from dens of vice. Virtuebreeding vice dens, where the energies of life flowed free, and the spontaneous self projected new worlds, wholly new gestures by which to imagine and communicate what a free life can be. Beyond the beauty of the music, the art of jazz eloquently testifies to how living freely involves exercising the spontaneous self.

\section{"IF I COULD TELL YOU WHAT IT MEANT"}

If Lao-Tzu said that those who know don't speak, and those who speak don't know, he must not know.

-Anonymous

Imagination is the inner voice through which we are connected to nature, and which speaks to us usually through preverbal utterances, presentiments ranging from dream-signs to art creations to scientific hypotheses. Imagination is ominous in the literal sense of the term. If we call it the voice of "abductive inference," Peirce's term for a third form of inference that he claimed is not reducible to deductive or inductive inference, we frame it logically, legitimating it as realism and pragmatism. But like the poets William Blake and Samuel Taylor Coleridge, the scientistsemiotician Peirce understood that nature had an inward side and that modern nominalistic science was unscientific to exclude the qualitative and inward side of nature in the name of mechanism.

In carving out the logic of abduction, dry logician Peirce found the missing link between that inner life the romantics celebrated in the face of modernizing nominalistic civilization and its objectivist opposite. More than a missing link, he found the very heart by which the two sides could again communicate. He found a way to give voice to the inner voice of nature, the inner voice whose eradication is a prime goal of the machine of modern civilization. And remarkably, he did so through a scientific conception of logic, considered as semeiotic.

For final purpose, you see, was evicted by nominalized mechanical civilization in name only. In reality it became the cryptoreligious, dark, inverted underside: the goal of antisocial Hate, with its one-sided avatar Homo competitor, and more recently, zoon automaton, who lives and dies by calculation, by the inner dictator of 
modern life, the mechanical other. Spontaneous intelligence, in living dialogue with its inner and outer environments, the reality that made us human-in awareness, in wonder-must be rendered a mere fiction by the calculating consciousness of the mechanical other. Yet the spontaneous intelligence of the living environment that formed the original generalized other to whom emergent humans attuned themselves remains the ineradicable reality of the human body, against which the automatic calculating consciousness of the mechanical other is an overweening infantile projection.

But imagination remains ominous, dark, brooding, often surfacing within one willy-nilly. It speaks from the whole brain, not simply the small, verbal portion, and from that deeper mind of nature incorporated both in the human brain and in the wider world to which that brain is indigenously made to be attuned. It involves vastly more than the verbal brain-sliver the philosophic tongue-lovers call language. Without imagination, without the ability to make those in-formed guesses or abductive inferences, science is impossible, for it is only through abductive inferences that new information validly enters science. File it all under "Omenclature."

The imaginative practice we call art is not about knowledge; it is about bodying forth feelings and embodying them in felt form. If artists really knew what it was they are impelled to bring to form, they wouldn't need to make art. They could be scholars. But being not-knowing beings, possessed by feelings they need to bring to awareness through embodying them, artists make art. They must make art. That is why the great modern dancer Isadore Duncan said, "If I could tell you what it meant, there would be no point in dancing it," and why the painter Barnett Newman stated, "Aesthetics is for the artists as ornithology is for the birds." Art feels what mind knows later, feels and gestures it into being in the signifying moment. In this sense great art does not imitate life, rather, it becomes life.

There is an inner necessity that grabs hold of the artist in the act of making art. But that inner necessity is itself an element of creation, not an already fixed form. That inner necessity is also in an active process of creation, indeed, is one of its psychopodia, "Soul limbs," determined to find form.

Though his work draws attention to the varieties of social influences on works of art and choices made in their production, Howard Becker's (2001) theoretical approach is also constrained by a limited nominalist view of signification as either conventions or instances, denying the possibility that "the work itself" lives in the signifying moment. Similarly, dreams are not simply passive neural "events," nor are they, as William Domhoff (2001:13-33) claims, "the accidental by-product of two great evolutionary adaptations, sleep and consciousness." Dreaming is a great mammal in-visioning achievement and practice, and touchstone to the living wildness within the human body (Halton 1992:119-39).

Consider D. H. Lawrence's description of "the business of art" as revealing "the relation between man and his circumambient universe, at the living moment." It could just as easily be a description of hunter-gatherer animism. Lawrence eloquently shows how art personifies the signifying moment, which ultimately is that triadic relation between person, situation, and emanating sign of spontaneous intelligence: 
The business of art is to reveal the relation between man and his circumambient universe, at the living moment. As mankind is always struggling in the toils of old relationships, art is always ahead of the "times," which themselves are always in the rear of the present moment.... When van Gogh paints sunflowers, he reveals, or achieves, the vivid relation between himself, as man, and the sunflower, as sunflower, at that quick moment of time. His painting does not represent the sunflower itself. We shall never know what the sunflower itself is. And the camera will visualize the sunflower far more perfectly than van Gogh can.... The vision on the canvas is a third thing, utterly intangible and inexplicable, the offspring of the sunflower itself and van Gogh himself. The vision on the canvas is for ever incommensurable with the canvas, or the paint, or van Gogh as a human organism, or the sunflower as a botanical organism. You cannot weigh nor measure nor even describe the vision on the canvas. It exists, to tell the truth, only in the much-debated fourth dimension. In dimensional space it has no existence. ... It is a revelation of the perfected relation, at a certain moment, between a man and a sunflower. It is neither man-in-the-mirror nor flower-in-themirror, neither is it above or below or across anything. It is in-between everything, in the fourth dimension.

And this perfected relation between man and his circumambient universe is life itself, for mankind. It has the fourth-dimensional quality of eternity and perfection. Yet it is momentaneousness. (Lawrence 1936:527)

"Momentaneousness," yet having the "fourth-dimensional quality of eternity and perfection," such is the wonder one experiences in the presence of art. Art is the living gesture of life, whether embodied in visual, musical, dramatic, or bodily form. As such, it is the living sign of the spontaneous gesture that is our birthright and ultimate human goal. For if life means anything more than sporting, in Darwin's sense, it has for its ultimate purport the participation in the ongoing creation of the universe. The Native American expression "To walk in beauty" conveys the ultimate aim of life far more accurately and deeply than the term knowledge, "possessed" by so-called Homo sapiens.

A little knowledge is a dangerous thing, the old adage goes. The same holds true for a being that would define itself as man "the knower." Man the maniac brainiac might be more accurate.

Consider again Oliver Sacks's words on music and narrative, from a case study of a retarded patient named "Rebecca":

The power of music, narrative and drama is of the greatest practical and theoretical importance. One may see this even in idiots, with IQs below 20 and the extremest motor incompetence and bewilderment. Their uncouth movements may disappear in a moment with music and dancing-suddenly, with music, they know how to move.... This procedural defect, or motor idiocy, as one might call it, which completely defeats any ordinary system of rehabilitative instruction, vanishes at once if music is the instructor. All this, no doubt, is the rationale, or one of the rationales, of work songs.

What we see, fundamentally, is the power of music to organ-ise-and to do this efficaciously (as well as joyfully!), when abstract or schematic forms of organisation fail. Indeed, it is especially dramatic, as one would expect, precisely when no other form of organisation will work. Thus music, or any other form of 
narrative, is essential when working with the retarded or apraxic-schooling or therapy for them must be centred on music or something equivalent. And in drama there is still more- there is the power of role to give organisation, to confer, while it lasts, an entire personality.The capacity to perform, to play, to be, seems to be a "given" in human life, in a way which has nothing to do with intellectual differences. One sees this with infants, one sees it with the senile, and one sees it, most poignantly, with the Rebeccas of this world. (Sacks 1987:185-66)

"The power of role to give organisation, to confer, while it lasts, an entire personality": isn't this just what Mead was attempting to say? Sacks's neurological cases lend support to Mead's developmental model of the self and the more general pragmatic outlook on biology and culture as a continuum rather than a dichotomy. But Sacks goes further to show what is usually completely passed over in discussions of social roles: he poignantly and eloquently illustrates the power of role, of its entrancing abilities while it lasts to transform the person.

Such entrancing is no mere social construction ideology, brainwashed into us, but stems from the deepest parts of our brains and evolutionary history (Barfield 1973). Consider, for example, that six billion humans - including you and me, dear readerand countless billions of mammals will dream entranced tonight, and tomorrow night, and every night, and would soon die if we did not. Is that "ephemeral"? The human body requires the stages of sleep, and the entrancing dream-consciousness that is an element of sleep, to survive and thrive.

For the conversation of gestures is ultimately at base the ability to entrance the other through ritual repartee. More, it is participation in the entrancing itself. It is the entrancement of attraction, of aggression, of hot intimacy in making love, of "psyching out" opponents in games and sports, of a 180-pound man conveying superior force to a 1,500-pound tiger, of a mother's gaze attuned to that of her infant, of the self-transcending "moments" of spectacle and public life. It is the rich undercurrent of bodily emotional signs that are ever present in human interaction, conveying precise, unworded information.

The conversation of gestures opens to the general conversation of nature, to the full symphony of participation consciousness that is nature's inner voice. Here, perhaps, we must leave Mead behind, though he opened the door to the deeper neurometaphysics of the conversation of nature.

The generalized other is not limited to the human community we internalize, that is the prejudice introduced by civilizational consciousness, enclosed, as it were, within its city walls of the mind. Nor is the generalized other reducible to the mechanical universe of modern life, incapable of conceiving generality - that is, signification - as real. The generalized other involves our participation in a living, signifying, circumambient environment, found originally in our attunement to and conversation with the animals and plants and elements on which we depended for our life. This original template was what the "biped who did not yet speak" conversed with, as the conversation of gestures evolved into the significant symbol of the human self. When we walked away from the attunement of the human to the greater-than- 
human, when we began that glorious march of history, of agriculturally based civilizations and anthropocentric consciousness, attuned to human power itself, we thought we left our "primitive" participation consciousness behind. But it remains an indelible aspect of human being, of self-originated experience, despite our current alienation from it. Real freedom is wild entrancement, found in these very bodies from which we walked ourselves out of the Pleistocene era, attuned to the greater-than-human environment of life: Wild entrancement in love and learning, in child development and in deepening maturity.

The earlier developmental stage of the conversation of gestures remains as an irreducible mode of bodying-forth communication, even as it is also embedded in the later conversation of significant gestures. For in music and dance and drama, and in the engaging rituals that punctuate public and private life, it is precisely the loss of self-reflection through entrancement that provides entrance to the fully participating, spontaneous self.

In the words of the medieval sufi poet Rumi:

We have fallen into the place

where everything is music.

Stop the words now.

Open the window in the center of your chest,

and let the spirits fly in and out. (1997:34-35)

\section{NOTE}

1. The first version of this article was presented at a session of the Society for the Advancement of American Philosophy. My thanks for comments from fellow panel members-all sociologistsHarold Orbach, Dmitri Shalin, and Hans Joas. The continued marginality of George Herbert Mead in American philosophy remains curious. I am also indebted to Arthur Glass for bringing the etymology of phronesis to my attention in an Internet discussion.

\section{REFERENCES}

Abram, David. 1997. The Spell of the Sensuous. New York: Vintage Books.

Barfield, Owen. 1973. The Rediscovery of Meaning: And Other Essays. Wesleyan, CT: Wesleyan University Press.

Bateson, Gregory. 1972. Steps Toward an Ecology of Mind. New York: Chandler.

Becker, Howard. 2001. "The Work Itself." http://home.earthlink.net/ hsbecker.

Birdwhistell, Ray L. 1970. Kinesics and Context: Essays in Body Motion Communication. Philadelphia: University of Pennsylvania Press.

Damasio, Antonio. 1994. Descartes' Error: Emotion, Reason and the Human Brain. New York: Harcourt and Brace.

. 1999. The Feeling of What Happens: Body and Emotion in the Making of Consciousness. New York: Harcourt and Brace.

- 2003. Looking for Spinoza: Joy, Sorrow and the Feeling Brain. New York: Harcourt and Brace.

Darwin, Charles. [1872] 1998. The Expression of the Emotions in Man and Animals. New York: HarperCollins. 
Domhoff, G. W. 2001. “A New Neurocognitive Theory of Dreams.” Dreaming 11:13-33.

Gadamer, Hans-Georg. 1980. Truth and Method. New York: Crossroads.

Gergen, Kenneth. 1991. The Saturated Self: Dilemmas of Identity in Contemporary Life. New York: Basic Books.

Hall, Edward T. 1959. The Silent Language. New York: Anchor Books.

-1967. The Hidden Dimension. New York: Anchor Books. 1983. Dance of Life: The Other Dimension of Time. New York: Anchor/Doubleday.

Halton, Eugene. 1986. Meaning and Modernity: Social Theory in the Pragmatic Attitude. Chicago: University of Chicago Press.

1992. "The Reality of Dreaming." Theory, Culture, and Society 9(3):119-39.

1995. Bereft of Reason: On the Decline of Social Thought and Prospects for Its Renewal. Chicago: University of Chicago Press.

2000. "Brain Suck." Pp. 93-109 in New Forms of Consumption, edited by M. Gottdiener. New York: Rowman and Littlefield.

- Forthcoming. "The Cosmic Fantasia of Life. In Going Public with Spirituality in Higher Education and Business, edited by D. K. Scott, S. M. Awbrey, and D. Dana. New York: Peter Lang.

Holler, Linda. 2002. Erotic Morality: The Role of Touch in Moral Agency. New Brunswick, NJ: Rutgers University Press.

Lawrence, D. H. 1936. Phoenix: The Posthumous Papers of D. H. Lawrence. Edited and with an introduction by E. D. McDonald. New York: Viking Press.

MacIntyre, Alasdair. 1981. After Virtue. Notre Dame: University of Notre Dame Press.

Mead, George Herbert. [1922] 1964. "A Behavioristic Account of the Significant Symbol." Pp. 240-47 in Mead: Selected Writings, edited by A. J. Reck. Indianapolis: Bobbs-Merrill. . 1934. Mind, Self, and Society. Edited by C. W. Morris. Chicago: University of Chicago Press.

Mingus, Charles. 1961. Charlie Mingus Presents Mingus. New York: Candid, CJM- 8005/CJS-9005.

Mokdad, Ali H., et al. 1999. "The Spread of the Obesity Epidemic in the United States, 19911998." Journal of the American Medical Association 282:1519-22.

Montagu, Ashley. 1978. Touching: On the Human Significance of Skin. New York: Harper.

Montagu, Ashley and Floyd Matson. 1983. The Dehumanization of Man. New York: McGraw-Hill.

Mumford, Lewis. 1967, 1970. The Myth of the Machine. Vol. 1: Technics and Human Development. Vol. 2: The Pentagon of Power. New York: Harcourt Brace Jovanovich.

Partridge, Eric. 1958. Origins: A Short Etymological Dictionary of Modern English. New York: Greenwich House.

Peirce, Charles Sanders. 1931. The Collected Papers of Charles Sanders Peirce, vol. 1. Edited by C. Hartshorne and P. Weiss. Cambridge, MA: Harvard University Press.

Rorty, Richard. 1989. Contingency, Irony, and Solidarity. New York: Cambridge University Press.

Rumi, Jalal al-Din. 1997. "Where Everything Is Music." Pp. 34-35 in The Essential Rumi, translated by C. Barks. San Francisco: HarperSan Francisco.

Sacks, Oliver. 1987. The Man Who Mistook His Wife for a Hat. New York: HarperPerennial.

Sahlins, Marshall. 1973. Stone-Age Economics. Chicago: Aldine.

Shepard, Paul. 1998. Coming Home to the Pleistocene. Edited by F. R. Shepard. Washington, DC: Island Press/Shearwater Books.

Stephens, Mitchell. 1992. “To Thine Own Selves Be True.” Los Angeles Times Magazine, August 23, p. 40.

Terkel, Studs. 1967. Division Street: America. New York: Pantheon.

Wittgenstein, Ludwig. [1921] 1974. Tractatus Logico-Philosophicus. Translated by D. F. Pears and B. F. McGuiness. London: Routledge and Kegan Paul. 